\title{
Inspiratory muscle relaxation rate assessed from sniff nasal pressure
}

\author{
D Kyroussis, G Mills, C H Hamnegard, S Wragg, J Road, M Green, J Moxham
}

\begin{abstract}
Background - Slowing of the maximum relaxation rate (MRR) of inspiratory muscles measured from oesophageal pressure (POES) during sniffs has been used as an index of the onset and recovery of respiratory muscle fatigue. The purpose of this study was to measure MRR at the nose (PNASAL MRR), to investigate its relationship with POES MRR, and to establish whether PNASAL MRR slows with respiratory loading.

Methods - Five normal subjects were studied. Each performed sniffs before and after two minutes of maximal isocapnic ventilation (MIV). In a separate session the subjects performed submaximal sniffs. PoES and PNASAL were recorded during sniffs and the MRR (\% pressure fall $10 \mathrm{~ms}$ ) for each sniff was determined.

Results - Before MIV mean POES MRR was 8.9 and PNASAL MRR was 9.3. The mean (SD) difference between PNASAL MRR and POES MRR during a maximal sniff was $0.48(0.34)(n=64)$ and during submaximal sniffs was $0 \cdot 28(0 \cdot 46)(n=526)$. The subjects showed a mean decrease in sniff POES MRR of $27 \cdot 4 \%$ (range $22 \cdot 5-36 \%$ ) after MIV and a similar reduction in sniff PNASAL MRR of $28 \cdot 5 \%$ (range $24 \cdot 1-41 \cdot 3 \%$ ). Both returned to control values within 5-10 minutes.
\end{abstract}

Conclusions - PNASAL MRR reflects POES MRR over a wide range of sniff pressures, PNASAL MRR of maximal sniffs reflects POES MRR in normal subjects at rest and following MIV, so measurement of PNASAL MRR may be a useful non-invasive method for measuring inspiratory muscle MRR, thereby providing an index of respiratory muscle fatigue.

(Thorax 1994;49:1127-1133)

Slowing of the maximum relaxation rate (MRR) of inspiratory muscles during sniffs has been used as an index of the onset and recovery of respiratory muscle fatigue. ${ }^{1-4}$ Sniff MRR is commonly calculated from oesophageal pressure traces (POES). This technique requires the positioning of a balloon-tipped catheter in the oesophagus. ${ }^{5}$ Less invasive methods of measuring have been reported using catheters in the nasopharynx or mouth. ${ }^{6}$ Recently the measurement of peak nasal pressure (PNASAL) in one occluded nostril has been shown to provide a close estimation of peak POEs during sniffs performed through the contralateral nostril. ${ }^{78}$
We measured MRR from pressures sampled at the nose (PNASAL MRR) during sniffs which varied in peak pressure, between $10 \%$ and $100 \%$ of each subject's maximum sniff PoEs, to investigate the agreement of the two methods over a wide range of sniff pressures. We also measured PNASAL MRR during maximal sniffs, before and after maximal isocapnic ventilation (MIV), to investigate its relationship with maximum sniff POEs MRR and to establish whether PNASAL MRR slows with respiratory muscle loading.

\section{Methods}

Five well trained members of our laboratory were recruited. All were non-smokers and without respiratory disease. The study was approved by the ethics committee of the Royal Brompton Hospital and all subjects gave informed consent.

Oesophageai pressure (PoEs) was measured using commercially available balloon-tipped catheters, $110 \mathrm{~cm}$ in length (PK Morgan, Rainham, Kent, UK), positioned in the standard manner. ${ }^{5}$ Nasal pressure (PNASAL) was measured using polythene catheters without distal balloons passed through a nasal cast (see below). Both catheters were connected to Validyne MP45-1 differential pressure transducers (range $\pm 200 \mathrm{~cm} \mathrm{H}_{2} \mathrm{O}$; Validyne Corporation, Northridge, California, USA) calibrated before each study using a Universal Pressure Meter (Bio-Tek Instruments Inc, USA) which was regularly tested for accuracy with a water manometer. All signals were displayed on a 12bit NB-M10-16 analogue digital board and a Macintosh Quadra 700 computer (Apple Computer Inc, Cupertino, California, USA) running LabVIEW software (National Instruments, Austin, Texas, USA).

We investigated whether the individual pressure transducer-amplifer systems could introduce errors into our results by linking the pressure inputs of the two catheter-transduceramplifier systems that were used for measuring pressures sampled in the oesophagus and the nose. We were then able to record simultaneously the same pressure signals during sniffs via the two systems and compare the data. Pressure amplitude, MRR, and non-normalised MRR were measured (see below for definitions). The mean (SD) ratio of the values derived from the two transducer-amplifier systems for pressure amplitude, MRR, and nonnormalised MRR were: $1.007(0.009), 0.992$ $(0.036), 0.998(0.030)$, respectively $(n=26)$.

Maximal isocapnic ventilation (MIV) was performed with apparatus previously de- 


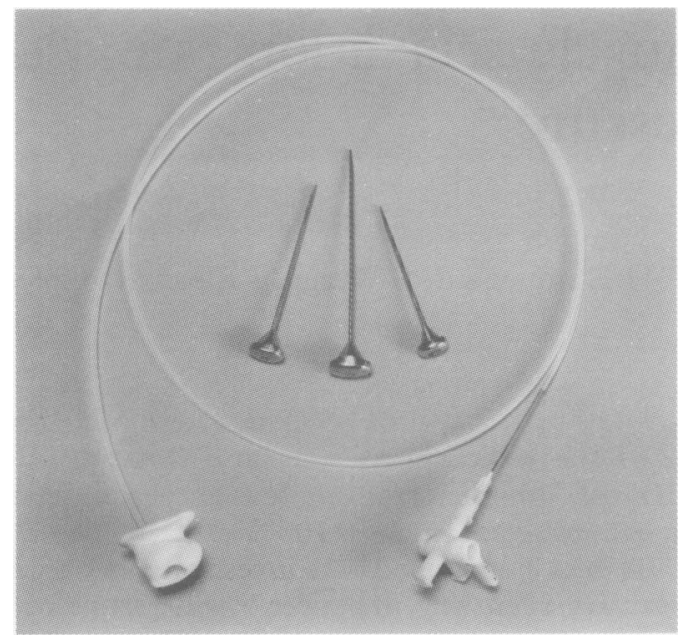

Figure 1 Three obturators of different size are shown in the centre of the photograph. The nasal cast is attached at one end of the polythene catheter.

scribed. ${ }^{3}$ Briefly, the subject inhaled from a six litre anaesthesia bag supplied with an air/ oxygen/carbon dioxide mixture. Inhaled gas composition and end tidal carbon dioxide tension $\left(\right.$ PeTCO $\left._{2}\right)$ were monitored with a HewlettPackard 78356A gas monitor (Hewlett-Packard Waltham, Massachusetts, USA). $\mathrm{PeTCO}_{2}$ was maintained at $5.5(0.5) \mathrm{kPa}$ by adjustment of the inhaled carbon dioxide concentration. The inhaled oxygen concentration was kept at $22(2) \%$.

A nasal cast was modelled for each subject to minimise pressure loss in the instrumented nostril and thereby enhance the agreement of sniff PNASAL with sniff PoEs. The cast was made from pliable silicon based elastomeric material (Optosil, Bayer Dental, Germany) and an activator liquid (Optosil-Xantopren activator, Bayer Dental). The material was gently placed in the selected nostril making an impression of the occupied space. A small obturator (fig 1) was inserted in the nostril before making the impression so that the material was prevented from being pushed too far up the nose. The obturator also served to form a tube through which a pressure catheter could be inserted and its tip kept away from the nasal cast and free of secretions. Once the material had hardened (3-6 minutes) the cast could be removed from the nostril.

\section{PROTOCOL}

All measurements were made with the subjects seated. Sniffs were performed from functional residual capacity (FRC) and no instructions were given regarding thoracoabdominal movement. ${ }^{9}$ Subjects were asked to perform sniffs of increasing effort from low to maximal pressure. The subjects performed at least 10 sniffs at each $10 \mathrm{~cm} \mathrm{H}_{2} \mathrm{O}$ increment until they reached their maximal sniff pressure. The MIV study was performed at a different session. All subjects were familiar with MIV from previous studies. Before the MIV run the subjects were asked to perform at least 10 maximal sniffs. The MIV run then lasted for two minutes. During this time the subjects were verbally encouraged to maintain the highest possible ventilation. Immediately upon stopping the MIV run maximal sniffs were performed from FRC every five seconds for five minutes and a further 10 sniffs were performed at 10 minutes. End expiration Poes was marked on the computer screen to help the subjects perform sniffs from FRC.

MRR was calculated as the maximal rate of decay of pressure/peak pressure, and had units of $\%$ pressure loss $/ 10 \mathrm{~ms} .{ }^{10-12}$ This normalisation of MRR for changes in pressure amplitude allows the comparison of MRR values of different peak pressure. In this study we were particularly interested in the comparison of PNASAL and POES MRR calculated from traces obtained from the same sniff. We therefore also looked at MRR values which had not been normalised for sniff amplitude (MRR $\mathrm{nC}) . M R R \mathrm{nC}$ was defined as the maximal rate of pressure decay/10 ms $(\mathrm{dP} / \mathrm{dt})$ and had units of $\mathrm{cm} \mathrm{H} \mathrm{H}_{2} \mathrm{O} / 10 \mathrm{~ms}$. MRR was obtained from PoEs and PNASAL sniffs that satisfied the following criteria: (1) sniff performed from FRC as judged by baseline POES before the sniff; (2) peak pressure maintained for less than $50 \mathrm{~ms}$; (3) total sniff duration less than $500 \mathrm{~ms}$; and (4) pressure waveform of sniff displaying smooth upstroke and decay curves. By these criteria $86.5 \%$ of sniffs were suitable for analysis from the MIV study and $89 \cdot 2 \%$ of sniffs were suitable for analysis from the study of sniffs of increasing pressure amplitude. Within-day reproducibility was assessed by three subjects repeating 10 maximal sniffs three times. Each session was separated by an interval of 30 minutes. Day-to-day reproducibility was assessed by repeating 10 maximal sniffs in three subjects on three separate days.

\section{STATISTICAL ANALYSIS}

In order to assess the agreement between PNASAL and POES MRR we calculated their differences for each sniff. The mean of these differences (d) is a measure of accuracy or bias whilst the standard deviation (SD) is a measure of precision. Both bias and precision are necessary to assess agreement. ${ }^{13}$ The limits between which $95 \%$ of differences will lie ("limits of agreement", $\mathrm{d} \pm 2 \mathrm{SD}$ ) were calculated, ${ }^{14}$ and the ratio of PNASAL to POES MRR was also calculated to compare the values of the two methods over the range of MRR observed. Data were presented by plotting the results of one method against those of the other (line of equality graph) and by plotting the differences between the methods against their mean. ${ }^{14}$ The day-to-day and within-day coefficients of variation of the ratio PNASAL/POES MRR were calculated to establish whether variations of POES MRR values are followed by a similar variation of PNASAL MRR.

\section{Results}

SNIFFS OF INCREASING EFFORT

MRR differences (nasal MRR-PoEs MRR), normalised and non-normalised, for each $10 \%$ 
Table 1 Mean (SD) differences of MRR values, normalised and non-normalised (nC), and ratios PNASAL MRR/POES $M R R$, normalised and non-normalised, from the study of sniffs of different efforts. The results are given for each $10 \%$ pressure increment as well as collectively for all data

\begin{tabular}{|c|c|c|c|c|c|}
\hline \multirow[b]{2}{*}{$\% \max P$} & \multicolumn{2}{|c|}{ PNASAL MRR-POES MRR } & \multicolumn{2}{|c|}{ PNASAL MRR/POES MRR } & \multirow[b]{2}{*}{$n$} \\
\hline & $M R R$ & $M R R n C$ & $n / o M R R$ & $n / o M R R n C$ & \\
\hline $10-20$ & $0.30(0.82)$ & $-0.04(0.12)$ & $1 \cdot 04(0 \cdot 12)$ & $0 \cdot 96(0 \cdot 10)$ & 32 \\
\hline $21-30$ & $0 \cdot 14(0.61)$ & $0.00(0 \cdot 15)$ & $1.02(0.08)$ & $1.00(0.06)$ & 45 \\
\hline $31-40$ & $0.27(0.54)$ & $0.02(0.19)$ & $1.03(0.06)$ & $1.00(0.06)$ & 62 \\
\hline $41-50$ & $0.25(0.47)$ & $0.03(0.28)$ & $1.03(0.06)$ & $1.01(0.07)$ & 75 \\
\hline $51-60$ & $0.21(0.33)$ & $-0.05(0.32)$ & $1.02(0.04)$ & $0.99(0.06)$ & 68 \\
\hline $61-70$ & $0.29(0.40)$ & $-0.08(0.63)$ & $1.03(0.04)$ & $0.99(0 \cdot 10)$ & 66 \\
\hline $71-80$ & $0.30(0.37)$ & $-0 \cdot 10(0.61)$ & $1.03(0.04)$ & $0.99(0.08)$ & 72 \\
\hline $81-90$ & $0.37(0.27)$ & $0.03(0.45)$ & $1.04(0.03)$ & $1.00(0.05)$ & 63 \\
\hline $91-100$ & $0 \cdot 40(0 \cdot 28)$ & $0.21(0 \cdot 42)$ & $1.05(0.03)$ & $1 \cdot 02(0.05)$ & 43 \\
\hline All data & $0.28(0.46)$ & $0.00(0.42)$ & $1.03(0.06)$ & $1 \cdot 00(0.07)$ & 526 \\
\hline
\end{tabular}

$M R R=$ maximum relaxation rate $(\%$ pressure drop $/ 10 \mathrm{~ms}) ; \mathrm{MRR} \mathrm{nC}=$ non-normalised $\mathrm{MRR}\left(\mathrm{cm} \mathrm{H}_{2} \mathrm{O} / 10 \mathrm{~ms}\right) ; \% \mathrm{max} \mathrm{P}=$ percentage of peak pressure of maximum sniffs; PNASAL = nasal pressure; POES = oesophageal pressure $\left(\mathrm{cm} \mathrm{H}_{2} \mathrm{O}\right) ; n / 0=P N A S A L$ Poes.

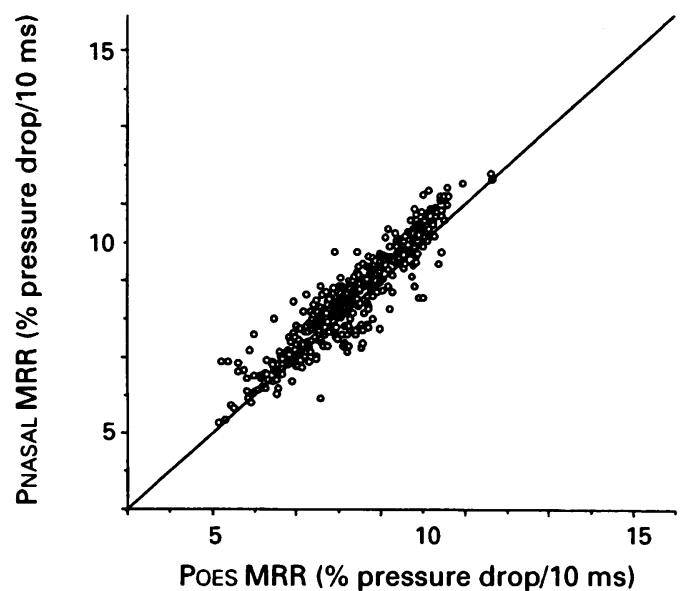

Figure 2 PNASAL MRR plotted against POES MRR. Data from the study of sniffs of increasing effort. The line of identity is also shown.

pressure increment are shown in table 1 . The ratios of PNASAL MRR/POES MRR for each $10 \%$ increment are also shown. Figure 2 shows PNASAL MRR plotted against PoEs MRR and fig 3 shows the same parameters non-normalised for pressure amplitude.

BASELINE SNIFFS

Table 2 shows the mean (SD) data before the MIV run: PNASAL and POES MRR, their mean (SD) differences, the $95 \%$ limits of agreement, and the ratio PNASAL/Poes MRR. The same calculations were also performed for non-normalised ( $\mathrm{nC}$ ) nasal and oesophageal MRR and for sniff peak pressure amplitudes (PNASAL, Poes). Sniff PNASAL MRR and Poes MRR were closely related. A close relationship was also shown between nasal and oesophageal peak pressures. Within-day coefficient of variation for the ratio PNASAL/PoES MRR assessed in three subjects for three study sessions was $2.9 \%$. The day-to-day coefficient of variation assessed in three subjects on three different days was $3 \cdot 3 \%$.

\section{MAXIMUM ISOCAPNIC VENTILATION (MIV) STUDY}

Figure 4 shows pressure traces obtained in the oesophagus and at the nose before, immediately after, and 10 minutes after MIV. The slopes of oesophageal and nasal pressure decay curves are similar. Immediately after muscle loading

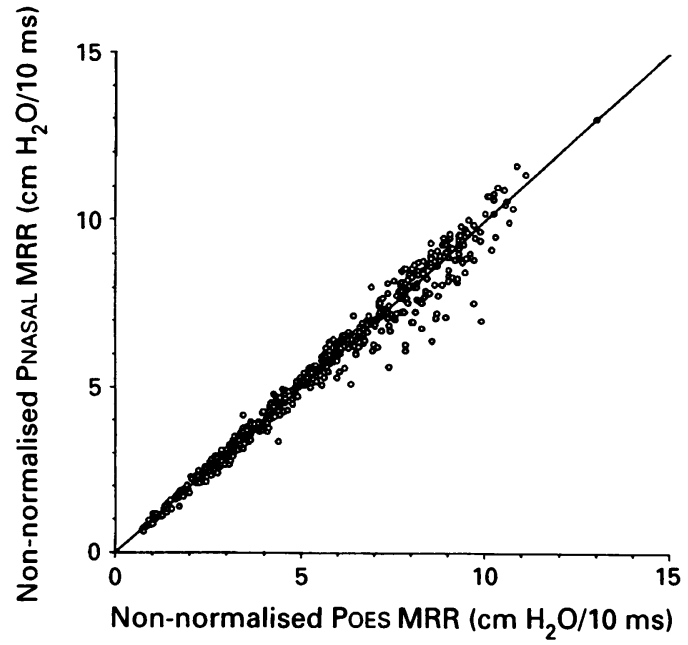

Figure 3 PNASAL MRR non-normalised for sniff pressure amplitude plotted against POES MRR non-normalised for sniff pressure amplitude. Data from the study of sniffs of increasing effort. The line of identity is also shown.

the slope changed in both traces and recovered 10 minutes after the MIV run. The subjects showed a mean decrease in sniff POES MRR of $27 \cdot 4 \%$ (range $22 \cdot 5-36 \%$ ) the first minute after MIV, which returned to control values within 5-10 minutes. A similar reduction and time course of recovery was observed for sniff PNASAL MRR, with a mean fall of $28.6 \%$ (range $24 \cdot 1-41 \cdot 3 \%$ ) (fig 5). PNASAL MRR and PoES MRR expressed as \% of baseline values during each minute after MIV, and PNASAL and POES expressed as \% of baseline values over the same time period are shown in table 3 . Table 4 shows

Table 2 Mean (SD) data from five subjects performing maximum sniffs before the maximum isocapnic ventilation serving as baseline values $(n=64)$

\begin{tabular}{|c|c|}
\hline $\begin{array}{l}\text { PNASAL MRR } \\
\text { POES MRR } \\
\text { PNASAL MRR-POES MRR } \\
\text { Limits of agreement }\end{array}$ & $\begin{array}{l}9 \cdot 30(1 \cdot 31) \\
8 \cdot 90(1 \cdot 21) \\
0 \cdot 48(0 \cdot 34) \\
1 \cdot 15 \text { to }-0 \cdot 19\end{array}$ \\
\hline $\begin{array}{l}\text { PNASAL MRR nC } \\
\text { POES MRR nC } \\
\text { PNASAL MRR nC-PoEs MRR nC } \\
\text { Limits of agreement }\end{array}$ & $\begin{array}{l}8 \cdot 90(1 \cdot 36) \\
8 \cdot 60(1 \cdot 24) \\
0 \cdot 25(0 \cdot 41) \\
1 \cdot 07 \text { to }-0.57\end{array}$ \\
\hline $\begin{array}{l}\text { PNASAL/POES MRR } \\
\text { PNASAL/POES MRR nC } \\
\text { PNASAL } \\
\text { POES } \\
\text { PNASAL/POES } \\
\text { PNASAL - POES } \\
\text { Limits of agreement }\end{array}$ & $\begin{array}{c}1.05(0.03) \\
1 \cdot 03(0.05) \\
96 \cdot 08(16.3) \\
98 \cdot 20(14.8) \\
0.97(0 \cdot 05) \\
-1 \cdot 88(3.64) \\
5.39 \text { to }-9 \cdot 15\end{array}$ \\
\hline
\end{tabular}

$M R R=$ maximum relaxation rate (\% pressure drop $/ 10 \mathrm{~ms}$ ) MRR $\mathrm{nC}=$ non-normalised $\mathrm{MRR}\left(\mathrm{cm} \mathrm{H}_{2} \mathrm{O} / 10 \mathrm{~ms}\right)$; PNASAL $=$ nasal pressure; POES = oesophageal pressure $\left(\mathrm{cm} \mathrm{H}_{2} \mathrm{O}\right)$. 

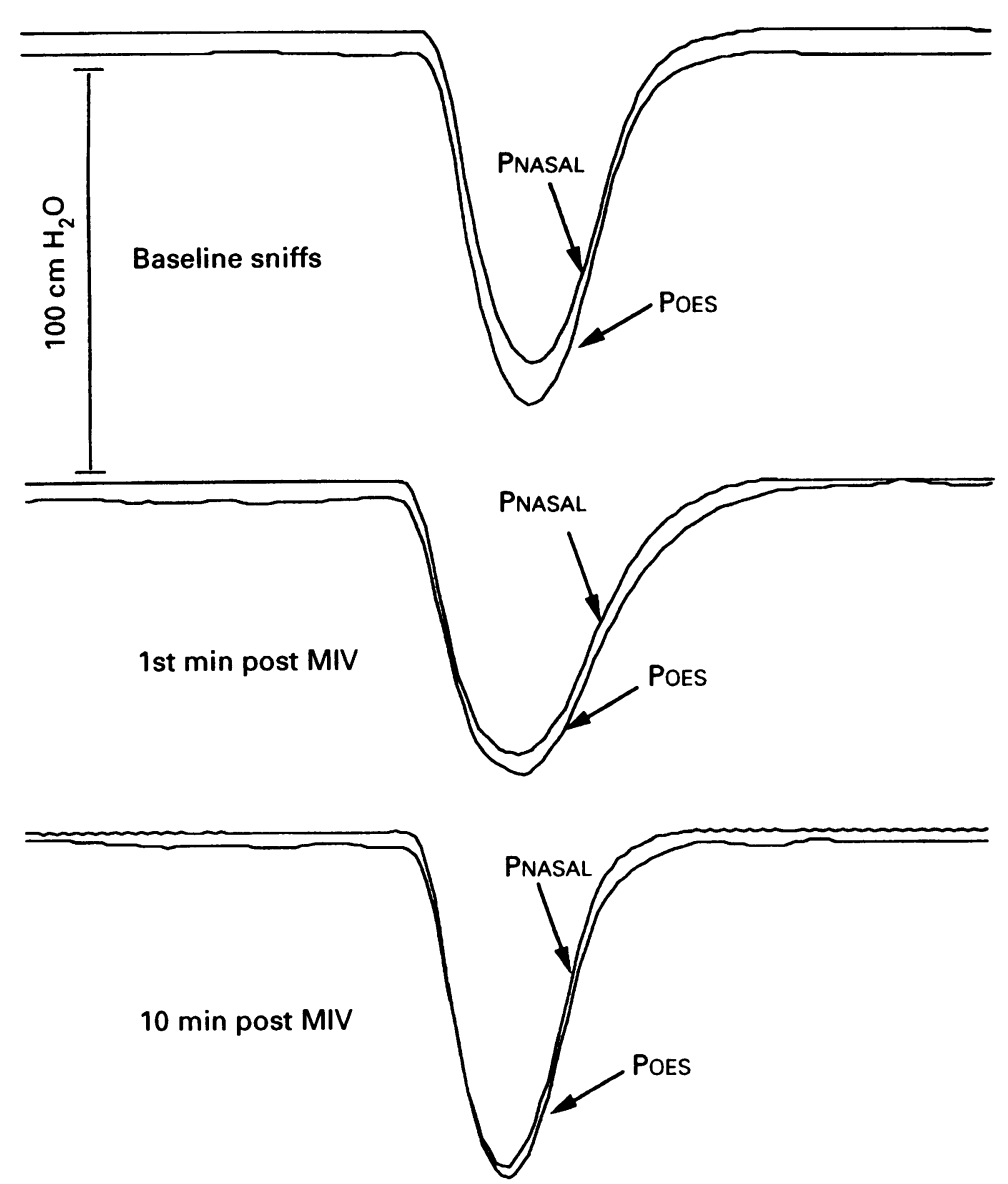

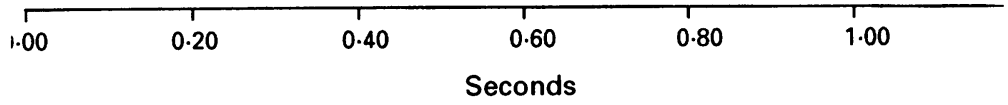

Figure 4 Pressure traces sampled at the nose and in the oesophagus before, during the first minute, and 10 minutes after muscle loading.

Table 3 Mean (SD) values of PNASAL MRR, POES MRR, peak PNASAL, and peak POES measured after maximal isocapnic hyperventilation. All values are expressed as percentage of baseline values

\begin{tabular}{lccrr}
\hline $\begin{array}{l}\text { Minutes } \\
\text { after }\end{array}$ & & & \\
MIV & PNASAL MRR & POES MRR & PNASAL & \multicolumn{1}{l}{ POES } \\
\hline 1 & $71(8 \cdot 8)$ & $73(9 \cdot 5)$ & $82(17 \cdot 0)$ & $82(18 \cdot 7)$ \\
2 & $76(6 \cdot 9)$ & $77(7 \cdot 5)$ & $89(15 \cdot 7)$ & $87(15 \cdot 5)$ \\
3 & $83(6 \cdot 3)$ & $84(6 \cdot 8)$ & $92(13 \cdot 2)$ & $91(13 \cdot 2)$ \\
4 & $85(8 \cdot 8)$ & $86(10 \cdot 1)$ & $90(12 \cdot 0)$ & $90(11 \cdot 2)$ \\
5 & $88(10 \cdot 1)$ & $89(10 \cdot 5)$ & $90(11 \cdot 6)$ & $90(11 \cdot 0)$ \\
10 & $103(13 \cdot 4)$ & $101(13 \cdot 1)$ & $101(12 \cdot 5)$ & $100(12 \cdot 3)$ \\
\hline
\end{tabular}

MIV = maximum isocapnic ventilation; $M R R=$ maximum relaxation rate; $P$ NASAL $=$ nasal pressure; POES $=$ oesophageal pressure $\left(\mathrm{cm} \mathrm{H}_{2} \mathrm{O}\right)$.

MRR differences (PNASAL - PoEs MRR), normalised and non-normalised for pressure amplitude, for the control values, for each minute after MIV, and for all the data. The ratio of normalised MRR to non-normalised MRR is also shown. Figure 6 shows PNASAL MRR plotted against POES MRR. Figure 7 shows the mean MRR values of the two methods plotted against their differences. Values for figs 6 and 7 correspond to measurements before and after the MIV run.

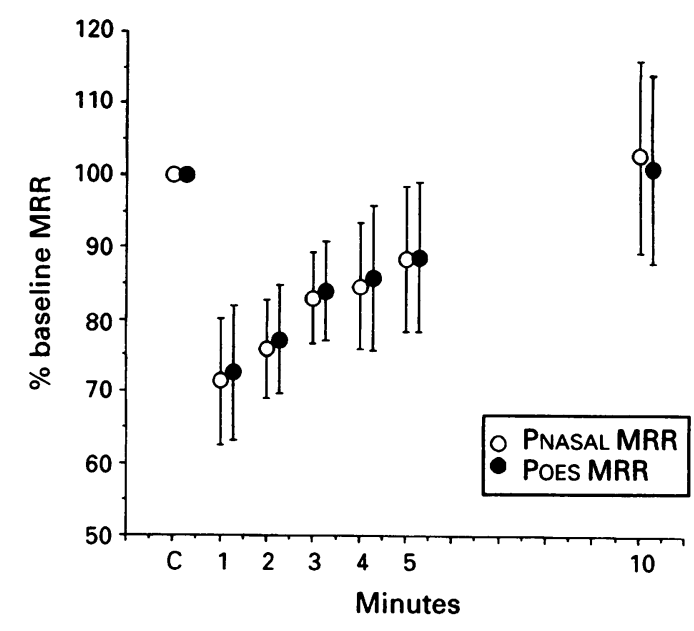

Figure 5 PNASAL and POES MRR values expressed as a percentage of the baseline values after MIV.A similar reduction and time course of recovery is observed for both POES MRR and PNASAL MRR.

\section{Discussion}

This study indicates good agreement between Poes MRR and PNASAL MRR in normal subjects over the whole range of pressure amplitudes for sniffs performed with increasing effort. After inspiratory muscle loading POES MRR slowed and returned to control values within 5-10 minutes and a similar slowing and time course of recovery was found for PNASAL MRR.

In this study we assumed that inspiratory muscle relaxation rate could be detected from the decay curve of pressure generated by voluntary inspiratory manoeuvres and that the peak pressure of sniff coincides with the beginning of the muscle relaxation phase. Earlier studies using simultaneous inspiratory muscle EMG and pressure recordings during occluded $^{1}$ and unoccluded sniffs ${ }^{2}$ showed that inspiratory muscle activity ceased at the peak pressure point and that the inspiratory muscles remained electrically silent during the decay portion of the pressure curve.

The similarity of pressures sampled in the upper airways and oesophagus during occluded inspiratory manoeuvres has been described in previous studies. ${ }^{51516}$ When an inspiratory effort is performed against an occlusion there is no airflow and therefore no pressure gradient between lower and upper airways. Although the unoccluded sniff is a dynamic manoeuvre, bulk flow is relatively small. During a sniff a large transnasal pressure gradient is created. The nostrils behave as a starling resistor, collapsing as a result of negative nasal pressure. ${ }^{17-19}$ It is estimated that $10-12 \mathrm{~cm} \mathrm{H}_{2} \mathrm{O}$ transnasal pressure leads to nostril collapse in the region between the junction of the pyriform aperture and the upper and lower lateral cartilages, $2.5 \mathrm{~cm}$ from the external orifice. ${ }^{18}$ Flow therefore reaches a plateau very early during sniff and stays unchanged until almost the end of the pressure decay curve, despite inspiratory muscle activity ceasing at the peak pressure point. ${ }^{2}$ The flow limitation during a sniff manoeuvre explains the similarity of pressure traces obtained from the oesophagus and the occluded nostril and the high pleural pressures developed during a sniff. ${ }^{9}$ 
Table 4 Mean (SD) differences of MRR values, normalised and non-normalised ( $n C)$, derived from nasal and oesophageal sniff pressure traces before and after the MIV run. The ratios of these parameters are also shown. Differences and ratios of the two methods for all data are shown at the bottom of the table.

\begin{tabular}{|c|c|c|c|c|c|}
\hline & \multicolumn{2}{|c|}{ PNASAL MRR-POES MRR } & \multicolumn{2}{|c|}{ PNASAL MRR/POES MRR } & \multirow[b]{2}{*}{$n$} \\
\hline & $M R R$ & $M R R n C$ & $n / o M R R$ & $n / o M R R n C$ & \\
\hline $\begin{array}{c}\text { Baseline } \\
11 \mathrm{~min} \\
2 \mathrm{~min} \\
3 \mathrm{~min} \\
4 \mathrm{~min} \\
5 \mathrm{~min} \\
10 \mathrm{~min} \\
\text { All data }\end{array}$ & $\begin{array}{l}0.48(0.34) \\
0.20(0.45) \\
0.23(0.31) \\
0 \cdot 27(0.32) \\
0.29(0.41) \\
0.40(0.35) \\
0.65(0.33) \\
0.38(0.38)\end{array}$ & $\begin{array}{l}0.25(0.41) \\
0.09(0.26) \\
0.13(0.32) \\
0.23(0.35) \\
0.13(0.42) \\
0.24(0.42) \\
0.55(0.55) \\
0.25(0.43)\end{array}$ & $\begin{array}{l}1.05(0.03) \\
1.03(0.06) \\
1.04(0.05) \\
1.03(0.04) \\
1.04(0.05) \\
1.05(0.04) \\
1.07(0.03) \\
1.05(0.04)\end{array}$ & $\begin{array}{l}1.03(0.05) \\
1.02(0.05) \\
1.02(0.06) \\
1.03(0.05) \\
1.02(0.06) \\
1.03(0.05) \\
1.05(0.05) \\
1.03(0.05)\end{array}$ & $\begin{array}{r}64 \\
31 \\
37 \\
44 \\
46 \\
40 \\
55 \\
317\end{array}$ \\
\hline
\end{tabular}

$\mathrm{MIV}=$ maximum isocapnic ventilation; $M R R=$ maximum relaxation rate; (\% pressure drop $/ 10 \mathrm{~ms}) ; \mathrm{MRR} \mathrm{nC}=\mathrm{non}$-normalised MRR (cm H $\left.\mathrm{H}_{2} \mathrm{O} / 10 \mathrm{~ms}\right)$; PNASAL = nasal pressure; POES = oesophageal pressure $\left(\mathrm{cm} \mathrm{H}_{2} \mathrm{O}\right)$.

Agreement between PNASAL and Poes MRR depends on two factors: the peak pressure achieved by the two methods and the peak rate of pressure decay (dP/dt, non-normalised MRR) derived from PNASAL and POES traces. Although peak pressures were very similar in our study, the small differences of $2-3 \mathrm{~cm} \mathrm{H}_{2} \mathrm{O}$ could explain some of the small differences in MRR. The agreement between non-normalised MRR for the two methods was therefore better than the agreement between normalised MRR, especially when pressure agreement was less than usual. A small difference was observed, usually due to the faster $\mathrm{dP} / \mathrm{dt}$ of the nasal trace. This constant difference could not be explained by differences in the measurement apparatus. During a brief inspiratory manoeuvre pharyngeal muscles contract to preserve the patency of the upper airways. ${ }^{2021}$ The rate at which PNASAL declines could be influenced by upper airway muscle relaxation as well as relaxation of the inspiratory muscles. There are data to suggest that upper airway muscles have a higher percentage of fast twitch fibres than the diaphragm and other inspiratory muscles. ${ }^{2223}$ As a consequence they are likely to have different fatigue, potentiation, and relaxation characteristics. ${ }^{24}$ It is possible that the fast relaxation rate of the upper airway muscles explains the slightly faster rate of decline in PNASAL traces although other factors, including asynchronous muscle activity, may also play a part. ${ }^{25}$ Furthermore, the better agreement between PNASAL and POES MRR found after

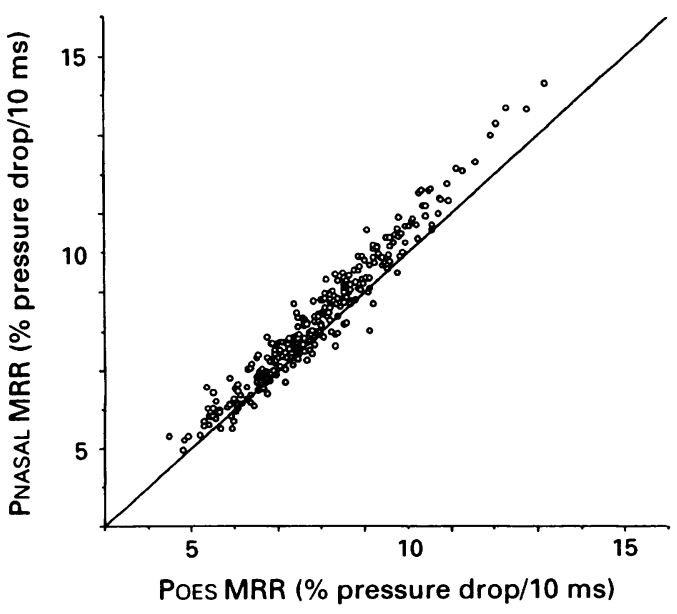

Figure 6 PNASAL MRR plotted against POES MRR. Data from MIV study. The line of identity is also shown. Values correspond to measurements before (baseline values) and after the MIV run.
MIV could reflect the greater fatiguability of the upper airway muscles, ${ }^{24}$ although we have no direct evidence to support this hypothesis.

Following MIV, in parallel with MRR slowing, a pressure decline was also observed. This pressure drop was relatively less than the fall in MRR, varied substantially between subjects, and tended to recover faster. These findings are in agreement with a previous study. ${ }^{3}$ Sniff pressure amplitude has an effect on MRR values. ${ }^{26}$ However, when sniff pressure exceeds $60 \%$ of maximum the effect of peak pressure on relaxation rate is minor. ${ }^{26}$ In the present study sniff peak pressures always exceeded $60 \%$ of maximum after MIV and the influence of sniff amplitude on the MRR was therefore negligible.

The change in lung volume, and consequently in muscle fibre length, observed during an unoccluded sniff could possibly influence MRR. In a recent study ${ }^{27}$ it was postulated that the small differences in MRR between occluded and unoccluded sniffs could be the result of differences in the degree of muscle shortening. However, other factors such as different patterns of muscle activation may play a part. ${ }^{27} \mathrm{We}$ are confident that differences of lung volume change that occur during a sniff before and after MIV are of such small magnitude that they cannot explain the changes in relaxation rate after muscle loading. Flow during a sniff is not dependent on the peak pressure amplitude because of the flow limiting

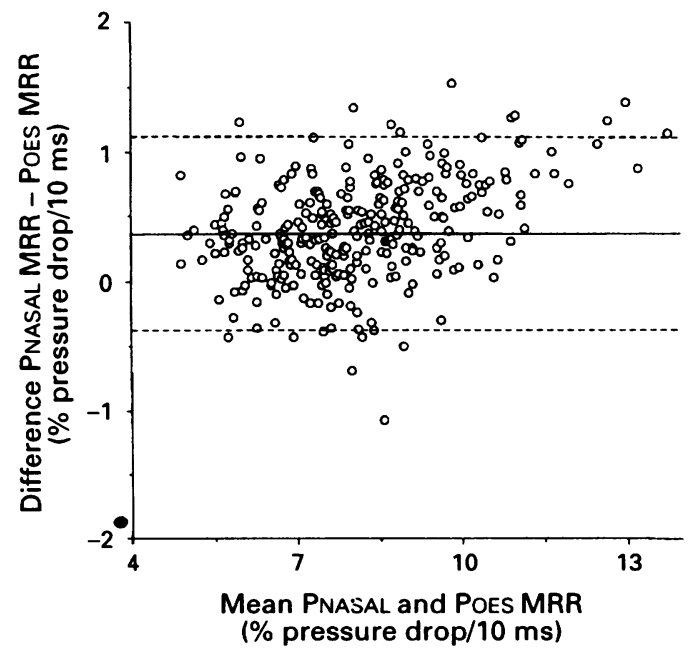

Figure 7 Mean PNASAL MRR and POES MRR values plotted against their differences. Data from MIV study. Values correspond to measurements before (baseline values) and after the MIV run. Limits of agreement $1 \cdot 14$ to -0.38 . 
mechanism in the nose, and the difference in gas expansion before and after MIV is likely to be trivial. Indeed, the increased duration of the sniff after the MIV might have contributed to an increased volume change and possibly a small underestimation of the fall in MRR.

We measured PNASAL and PoEs MRR over a wide range of pressure amplitudes to investigate the agreement of the two measurements. Even in sniffs of very low effort when pressure amplitudes of 10 or $20 \mathrm{~cm} \mathrm{H}_{2} \mathrm{O}$ were created, MRR and pressure values were very closely related and showed a similar agreement to those found during maximal sniffs. This suggests that the starling resistor mechanism can function adequately at low pressures. Nasal collapse probably occurs at a lower transnasal gradient when only one nostril is open during an inspiratory manoeuvre. ${ }^{28}$

MRR measurements from pressures sampled within the mouth and nasopharynx using balloon-tipped catheters have recently been reported. ${ }^{2}$ However, measurements derived from a balloon-tipped catheter in the mouth may be affected by suction and the positioning of a balloon in the nasopharynx is relatively uncomfortable.

In some instances PNASAL was slightly greater than POES. In one subject the nasal trace was sometimes distorted during maximal sniffs showing prolonged peak pressures and fast MRR. Both observations are likely to be the result of vigorous upper airway and neck muscle recruitment and were not observed in submaximal sniffs.

Activation of the expiratory muscles during the relaxation phase might falsely increase $M R R$ in cases in which the rise of tension of expiratory muscles exceeds the rate of decline in inspiratory muscles. However, activation of the expiratory muscles can be easily identified and the sniff rejected when PoEs becomes more positive than that at end expiratory pressure. ${ }^{25}$ The inability to exclude the above phenomenon is a limitation of measuring MRR from nasal pressure traces. In normal subjects this rarely causes a problem but in patients with chronic obstructive pulmonary disease (COPD) recruitment of the abdominal muscles is common during expiration and activation of this muscle group during the sniff relaxation phase occurs more frequently. ${ }^{25}$ Falsely high PNASAL MRR values might therefore be difficult to identify.

Previous studies have shown that the equilibrium of pressures measured in the oesophagus and the upper airways is a function of airway resistance and extrathoracic airway compliance (time constant for pressure equilibrium). ${ }^{29-31}$ In patients with COPD pressures measured in the oesophagus and the upper airways show a poor level of agreement ${ }^{25}$ and, as a consequence, upper airway pressure $M R R$ will be falsely high. To avoid the error introduced by the pressure discrepancy non-normalised MRR (dP/dt) of the upper airway and the oesophagus could be compared. In this case a good agreement would be expected unless there is vigorous recruitment of upper airway and neck muscles as during maximum sniffs. ${ }^{25}$ Our results show a good agreement between non-normalised PNASAL MRR and POEs MRR in very low sniff efforts. It therefore seems reasonable to hypothesise that inspiratory manoeuvres that require little effort will minimally recruit these muscle groups, thus enhancing the agreement of the two parameters. Studies designed to confirm this hypothesis would be of clinical importance.

We conclude that PNASAL MRR obtained from a maximal sniff accurately reflects POES MRR. PNASAL MRR can be used as an index of the onset and recovery of respiratory muscle fatigue in normal subjects. The fact that an oesophageal balloon is not necessary makes the studies easy to perform. We also conclude that PNASAL MRR accurately reflects POES MRR over a wide range of sniff pressures created by graded effort. The similarity between nasal and oesphageal peak pressure decay $(\mathrm{dP} / \mathrm{dt})$ recorded during sniffs of low effort could make this a useful method for non-invasively measuring MRR in patients with COPD.

1 Esau SA, Bye PTP, Pardy RL. Changes in rate of relaxation of sniffs with diaphragmatic fatigue in humans. $\mathcal{f} A p p$ Physiol 1983;55:731-5.

2 Koulouris N, Vianna LG, Mulvey DA, Green M, Moxham J. Maximal relaxation rates of esophageal, nose, and mouth pressures during a sniff reflect inspiratory muscle fatigue. Am Rev Respir Dis 1989;139:1213-7.

3 Mulvey DA, Koulouris NG, Elliott MW, Laroche CM Moxham J, Green M. Inspiratory muscle relaxation rate after voluntary maximal isocapnic ventilation in humans. f Appl Physiol 1991;70:2173-80.

4 Levy RD, Esau SA, Bye PTP, Pardy RL. Relaxation rate of mouth pressure with sniffs at rest and with inspiratory muscle fatigue. Am Rev Respir Dis 1984;130:38-41.

5 Milic-Emili J, Mead J, Turner JM, Glauser EM. Improved technique for estimating pleural pressure from esophageal technique for estimating pleural pressure

6 Koulouris N, Mulvey DA, Laroche CM, Sawicka EH, Green M, Moxham J. The measurement of inspiratory muscle strength by sniff esophageal, nasopharyngeal, and mouth pressures. Am Rev Respir Dis 1989;139:641-6.

7 Heritier F, Rahm F, Pasche P, Fitting JW. Sniff nasal inspiratory pressure: a non invasive assessment of inspiratory muscle strength. Am $\mathcal{F}$ Respir Crit Care Med (in press).

8 Hamnegård C-H, Wragg S, Kyroussis D, Road J, Moxham J, Green M. Assessment of inspiratory muscle strength by the sniff nasal inspiratory pressure. Eur Respir $\mathcal{f} 1993$; 6(Suppl 17):193s.

9 Miller JM, Moxham J, Green M. The maximal sniff in the assessment of diaphragm function in man. Clin Sci 1985; 69:91-6.

10 Edwards RHT, Hill DK, Jones DA. Metabolic changes associated with the slowing of relaxation in fatigued mouse muscle. ₹ Physiol 1975;251:287-301.

11 Wiles CM, Young A, Jones DA, Edwards RHT. Relaxation rate of constituent muscle fibre types in human quadriceps. rate of constituent muscle

12 Jewell BR, Wilkie DR. The mechanical properties of relaxing muscle. F Physiol 1960;152:30-47.

13 Altman DG. Analysing data. In: Statistics in practice. London British Medical Association, 1985:12-14.

14 Bland JM, Altman DG. Statistical methods for assessing agreement between two methods of clinical measurement. Lancet 1986; i:307-10.

15 Baydur A, Behrakis PK, Zin WA, Jaeger M, Milic-Emili J. A simple method of assessing the validity of the esophageal A simple method of assessing the validity of the esophageal

16 Marazzini L, Cavestri R, Gori D, Gatti L, Longhini E. Difference between mouth and esophageal occlusion pressure during $\mathrm{CO}_{2}$ rebreathing in chronic obstructive pulmonary disease. Am Rev Respir Dis 1978;118:1027-33.

17 Bridger GP. Physiology of the nasal valve. Arch Otolaryngol 1970;92:543-53.

18 Bridger GP, Proctor DF. Maximum nasal inspiratory flow and nasal resistance. Ann Otol Rhinol Laryngol 1970;79. 481-8.

19 Haight JSJ, Cole P. The site and function of the nasal valve. Laryngoscope 1983;93:49-55.

20 Remmers JE, deGroot WT, Sauerland EK, Anch AM Pathogenesis of upper airway occlusion during sleep. $\dot{f}$ Appl Physiol 1978;44:931-8.

21 Van Lunteren E, Strohl KP. The muscles of the upper airways. Clin Chest Med 1986;7:171-88.

22 Dick TE, van Lunteren E. Fiber subtype distribution of pharyngeal dilator muscles and diaphragm in cat. $\mathcal{F} A p p$ Physiol 1990;68:2237-40.

23 Van Lunteren E, Salomone RJ, Manubay P, Supinski GS 
Dick TE. Contractile and endurance properties of geniohyoid and diaphragm muscles. $\mathcal{F}$ Appl Physiol 1990; 69:1992-7.

24 Van Lunteren E, Vafaie $H$. Force potentiation in respiratory muscles: comparison of diaphragm and sternohyoid. $\mathrm{Am}$ F Physiol 1993;264:R1095-100.

25 Mulvey DA, Elliott MW, Koulouris NG, Carroll MP, Moxham J, Green $M$. Sniff esophageal and nasopharyngeal pressures and maximal relaxation rates in patients with respiratory dysfunction. Am Rev Respir Dis 1991;143: 950-3.

26 Mulvey D, Koulouris N, Elliott M, Moxham J, Green M. Maximal relaxation rate of inspiratory muscle can be Maximal relaxation rate of inspiratory muscle can be effort-dependent and reflect the activation
fibers. Am Rev Respir Dis 1991;144:803-6.

27 Mador MJ, Kufel TJ. Effect of inspiratory muscle fatigue on inspiratory muscle relaxation rate in healthy subjects. Chest 1992;102:1767-73.

28 Heritier F, Perret C, Fitting JW. Esophageal and mouth pressure during sniffs with and without nasal occlusion. Respir Physiol 1991;86:305-13.

29 Jaeger MJ. Effect of the cheeks and the compliance of alveolar gas on the measurement of respiratory variables. Respir Physiol 1982;47:325-340.

30 Murciano D, Aubier M, Bussi S, Derenne JP, Pariente R, Milic-Emili J. Comparison of esophageal, tracheal and mouth occlusion pressure in patients with COPD during mouth occlusion pressure in pev Respir Dis 1982:126: acute respiratory failure. Am Rev Respir Dis 1982;126:

31 Rodenstein DO, Stanescu DC, Francis C. Demonstration of failure of body plethysmography in airway obstruction. f Appl Physiol 1982;52:949-54.

\section{The case of the Queen's head: a confession}

As befits a building erected in the last century, the old Brompton Hospital was graced by a bust of Queen Victoria which stood on a plinth in an alcove in the main corridor. One night, three decades ago, the bust disappeared!

In the autumn of 1963 two young Brompton housemen were returning unsteadily to their rooms after enjoying a game of rugby and a convivial evening with their bibulous colleagues. The oriental combat sport of "kung fu" was in fashion at that time and, fired by an exuberance of spirit, one of the young friends jokingly aimed a blow at the Queen's bust as he passed along the corridor. To his amazement, his glancing blow decapitated the Queen and her head fell to the ground!

The night porter in his office at the hospital door was sleeping, and no one seemed to have heard the commotion. The malefactors were faced with the evidence of their wrongdoing and the prospect of chastisement on the following day. The abrupt termination of promising careers was a sobering thought and, following a hurried consultation, they decided to hide the fruits of their folly. Acting with urgent common purpose, they carried the bust and the head past the sleeping porter and buried them in the flower bed at the side of the driveway to the main hospital entrance.

On the following day the Queen's plinth stood glaringly empty in its alcove, but the absence of the bust went unnoticed and attracted no comment whatsoever. Five months later, with their crime undetected, the young men went their separate ways and both eventually achieved full professorial status in their chosen fields.

A decade after the heinous crime one of the perpetrators was passing through London on his way back to his new home on the other side of the world. In a fit of nostalgia and acting on impulse, he took a taxi to the Brompton Hospital, secretively exhumed the Queen's head, and carried it away. For the past 20 years the Queen has reposed in a quiet garden in a faraway part of her former Empire. She seems happy in this environment and it is the repentant but necessarily anonymous author's earnest hope that the Brompton Hospital governors will neither seek retributon nor insist upon her return. (The Statute of Limitations and the precedent of the Elgin marbles may be relevant.) 